\title{
2019 - Ihre Fachkunde läuft ab? Dann aktualisieren Sie Ihre Kenntnisse im Strahlenschutz einfach beim Röntgenkongress!
}

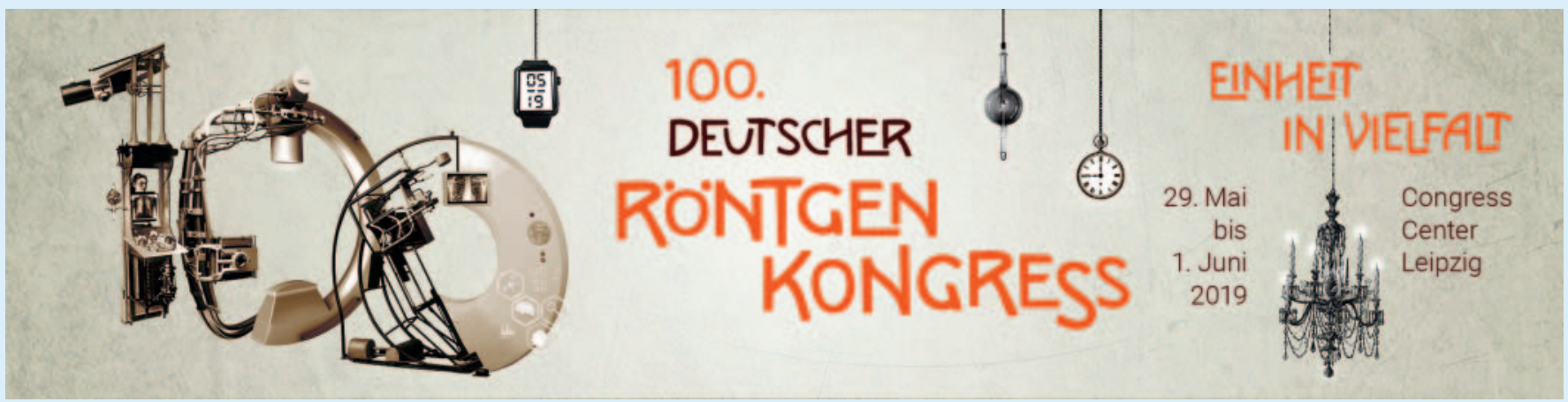

\section{Termine}

Mittwoch, 29. Mai 2019 ab 8:30 Uhr

Sie haben die Möglichkeit mit dem Besuch der entsprechenden Module Ihre Fachkunde zu aktualisieren:

08:30 - 11:45 Uhr - Modul A „Strahlenschutzrecht" (FK 101) - für jeden Pflicht!

12:00 - 15:15 Uhr - Modul C „Umgang mit Röntgengeräten“ (FK 102 und FK 103)

16:30 - 19:30 Uhr - Modul B „Tätigkeiten in der Strahlentherapie und Nuklearmedizin“ (FK 104)

Anmerkung: Die alten Richtlinien nach RöV und StrSchV werden sinngemäß angewendet, bis eine neue Richtlinie erarbeitet wird. Die Module B und C entsprechen den alten
Fachkundeaktualisierungen gemäß RöV (Modul C) und StrSchV (Modul B).

Sie besuchen die Modulkombination und legen am Ende alle Prüfungen ab:

\begin{tabular}{l|l}
\hline$A+B+C$ & $\begin{array}{l}\text { für Tätigkeiten in der Strah- } \\
\text { lentherapie und Nuklear- } \\
\text { medizin und Umgang mit } \\
\text { Röntgengeräten }\end{array}$ \\
\hline$A+B$ & $\begin{array}{l}\text { für Tätigkeiten in der } \\
\text { Strahlentherapie und } \\
\text { Nuklearmedizin }\end{array}$ \\
\hline$A+C$ & $\begin{array}{l}\text { für Umgang mit } \\
\text { Röntgengeräten }\end{array}$ \\
\hline
\end{tabular}

Am Ende der jeweiligen Module B und $C$ am 29. Mai 2019 legen Sie alle Prüfungen zu den Modulen A, B und/oder C ab. Die Prüfungsbögen übergeben Sie den Hostessen am Saalausgang. Wenn ein Prüfungsbogen fehlt, kann die Fachkunde nicht als aktualisiert bestätigt werden. Bei bestandener Prüfung schicken wir Ihnen die Teilnahmebescheinigungen per Post zu.

\section{Anmeldung}

Die Anmeldung erfolgt im Rahmen Ihrer Kongressanmeldung auf roentgenkongress. de > Anmeldung. Sollten Sie bereits gebucht haben, so können Sie sich erneut einloggen und diese Ihrer Buchung hinzufügen.

\section{Kosten}

\begin{tabular}{|l|c|c|c|}
\hline Fachkundeaktualisierung & Modul A+C & Modul A+B & Modul A+B + C \\
\hline Fachärztin/-arzt (DRG-Mitglied) & $120,-€$ & $120,-€$ & $180,-€$ \\
\hline Fachärztin/-arzt (kein Mitglied) & $180,-€$ & $180,-€$ & $250,-€$ \\
\hline MTRA (VMTB-Mitglied): & $90,-€$ & $90,-€$ & $150,-€$ \\
\hline MTRA (kein Mitglied): & $130,-€$ & $130,-€$ & $180,-€$ \\
\hline
\end{tabular}

